\title{
Accelerated puberty and late-onset hypothalamic hypogonadism in female transgenic skinny mice overexpressing leptin
}

\author{
Shigeo Yura, ${ }^{1}$ Yoshihiro Ogawa, ${ }^{2}$ Norimasa Sagawa, ${ }^{1}$ Hiroaki Masuzaki, ${ }^{2}$ Hiroaki Itoh, ${ }^{1}$ \\ Ken Ebihara, ${ }^{2}$ Megumi Aizawa-Abe, ${ }^{2}$ Shingo Fujii, ${ }^{1}$ and Kazuwa Nakao ${ }^{2}$ \\ ${ }^{1}$ Department of Gynecology and Obstetrics, and \\ ${ }^{2}$ Department of Medicine and Clinical Science, Kyoto University Graduate School of Medicine, Kyoto 606-8507, Japan \\ Address correspondence to: Norimasa Sagawa, Department of Gynecology and Obstetrics, Kyoto University Graduate School \\ of Medicine, 54 Shogoin Kawahara-cho, Sakyo-ku, Kyoto 606-8507, Japan. Phone: 81-75-751-3268; Fax: 81-75-761-3967; \\ E-mail: fetus@kuhp.kyoto-u.ac.jp. \\ Shigeo Yura and Yoshihiro Ogawa contributed equally to this work. \\ Received for publication September 7, 1999, and accepted in revised form February 1, 2000.
}

\begin{abstract}
Excess or loss of body fat can be associated with infertility, suggesting that adequate fat mass is essential for proper reproductive function. Leptin is an adipocyte-derived hormone that is involved in the regulation of food intake and energy expenditure, and its synthesis and secretion are markedly increased in obesity. Short-term administration of leptin accelerates the onset of puberty in normal mice and corrects the sterility of leptin-deficient $o b / o b$ mice. These findings suggest a role for leptin as an endocrine signal between fat depots and the reproductive axis, but the effect of hyperleptinemia on the initiation and maintenance of reproductive function has not been elucidated. To address this issue, we examined the reproductive phenotypes of female transgenic skinny mice with elevated plasma leptin concentrations comparable to those in obese subjects. With no apparent adipose tissue, female transgenic skinny mice exhibit accelerated puberty and intact fertility at younger ages followed by successful delivery of healthy pups. However, at older ages, they develop hypothalamic hypogonadism characterized by prolonged menstrual cycles, atrophic ovary, reduced hypothalamic gonadotropin releasing hormone contents, and poor pituitary luteinizing hormone secretion. This study has demonstrated for the first time to our knowledge that accelerated puberty and late-onset hypothalamic hypogonadism are associated with chronic hyperleptinemia, thereby leading to a better understanding of the pathophysiological and therapeutic implication of leptin.
\end{abstract}

J. Clin. Invest. 105:749-755 (2000).

\section{Introduction}

Adequate mass of adipose tissue is required for the onset of puberty and maintenance of fertility. A number of studies have indicated that undernourished children have delayed puberty (1) and that loss of body fat in adulthood often leads to impaired reproductive function $(2,3)$. However, it has been recognized that reproductive failure is also associated with obesity (4). Obese women often exhibit abnormal menstrual cycles and infertility, with reduced plasma luteinizing hormone (LH) levels and impaired LH secretion in response to exogenous gonadotropin releasing hormone ( $\mathrm{GnRH})$ (5), suggesting the involvement of hypothalamic-pituitary dysfunction in obesity-related reproductive failure.

The adipose tissue has been regarded as the site of triglyceride storage and FFA/glycerol release in response to energy demand (6). It also participates in a variety of homeostatic processes as an endocrine organ that secretes a number of biologically active hormones, cytokines, and growth factors $(6,7)$. Leptin is an adipocyte-derived hormone that is involved in the regulation of food intake and energy expenditure (8-12). It may act also as an important regulator of neuroen- docrine and reproductive functions. Leptin-deficient $o b / o b$ mice exhibit infertility caused by hypothalamic dysfunction (13), which is corrected by exogenous administration of leptin $(14,15)$. Short-term administration of leptin accelerates the onset of puberty in normal mice (16, 17) and rescues the impaired reproductive homeostasis in fasted mice and rats with reduced amounts of leptin (18-20). Furthermore, with a transient elevation of plasma leptin concentrations prior to a variety of pubertyrelated changes in neuroendocrine function, it is postulated that the "leptin surge" in childhood may signal the initiation of puberty $(21,22)$. Therefore, leptin may serve as an endocrine signal between fat depots and reproductive axis. However, to our knowledge the long-term effect of leptin on reproductive function has never been investigated. Plasma leptin concentrations are markedly increased in proportion to the degree of adiposity (23-25). The diurnal rhythmicity of plasma leptin concentrations is blunted in obesity, suggesting the involvement of continuous hyperleptinemia in obesity-related phenotypes (26). From this perspective, the effect of hyperleptinemia on the initiation and maintenance of reproductive function remains to be elucidated. 
We have recently produced transgenic mice overexpressing leptin under the control of the liver-specific promoter and demonstrated that chronic hyperleptinemia results in the complete disappearance of white and brown adipose tissue over the long term (27). We therefore call these animals transgenic skinny mice. They also exhibit increased glucose metabolism and insulin sensitivity accompanied by a marked increase in insulin signaling for glucose homeostasis in the skeletal muscle and liver $(27,28)$. Thus, transgenic skinny mice will provide the unique experimental model system with which to assess the long-term effect of leptin in vivo. To explore the long-term effect of hyperleptinemia on reproductive function, we have examined the reproductive phenotypes of female transgenic skinny mice overexpressing leptin.

\section{Methods}

Transgenic skinny mice. Generation of transgenic skinny mice overexpressing leptin under the control of the liver-specific human serum amyloid $\mathrm{P}$ component (SAP) promoter has been reported previously (27). The human SAP promoter is highly specific to the liver and is active only after birth (29). In this study, female and male transgenic skinny mice with 30 copies of the transgene were used as heterozygotes and maintained on standard rat chow (CE-2; $352 \mathrm{kcal} / 100 \mathrm{~g}$; Japan CLEA, Tokyo, Japan) under a 12-hour light (0800-2000 hours)/12-hour dark (2000-0800 hours) cycle. All experimental procedures were approved by the Kyoto University Graduate School of Medicine Committee on Animal Research.

Experimental designs. To determine the date of vaginal opening in female transgenic and nontransgenic littermates, mice were weaned at 21 days of age, and the vagina of each mouse was inspected daily (16). The durations of estrous cycles were also determined by inspection of daily vaginal smears. At the indicated ages, ovaries and uteri were removed from female transgenic and nontransgenic littermates and weighed. Ovarian weights were described as the total for the

Table 1

Fertility rate and number of pups in transgenic and nontransgenic littermates

\begin{tabular}{lccc}
\hline & & Fertility rate & Number of pups \\
Female & & & \\
8 weeks old & NonTg & $6 / 7$ & $6.0 \pm 0.8(n=6)$ \\
& $\mathrm{Tg}$ & $19 / 25$ & $5.0 \pm 0.5(n=19)$ \\
22 weeks old & $\mathrm{NonTg}$ & $5 / 7$ & $7.4 \pm 1.0(n=5)$ \\
& $\mathrm{Tg}$ & $2 / 12^{\mathrm{A}, \mathrm{B}}$ & $8.0(n=2)$ \\
Male & & & \\
8 weeks old & $\mathrm{NonTg}$ & $\mathrm{ND}$ & $\mathrm{ND}$ \\
& $\mathrm{Tg}$ & $14 / 15$ & $7.9 \pm 0.2(n=14)$ \\
22 weeks old & $\mathrm{NonTg}$ & $8 / 10$ & $6.9 \pm 1.0(n=8)$ \\
& $\mathrm{Tg}$ & $18 / 24$ & $6.8 \pm 0.5(n=18)$
\end{tabular}

$\mathrm{Tg}$, transgenic skinny mice; nonTg, nontransgenic littermates; $\mathrm{ND}=$ not determined. ${ }^{A} P<0.005$ compared with Tg at 8 weeks of age by $\chi^{2}$ test. ${ }^{B} P<0.05$ compared with nonTg at $22 \mathrm{wk}$ of age by $\chi^{2}$ test. bilateral ovaries. To assess the fertility rate, female transgenic and nontransgenic littermates at the indicated ages were mated with proved C57BL/6J breeder males for 3 weeks ( 2 males per cage).

We also examined the reproductive phenotypes of male transgenic skinny mice at older ages. The testes were removed from 26-week-old male transgenic and nontransgenic littermates and weighed. The fertility rate of male mice was also assessed by mating them with wild-type female mice for 3 weeks ( 2 females per cage).

To determine hypothalamic GnRH contents in transgenic and nontransgenic littermates, the whole hypothalami removed from mice at the indicated ages, immediately frozen in liquid nitrogen, and stored at $-70^{\circ} \mathrm{C}$ until use. Tissues were homogenized in $1 \mathrm{~N}$ acetic acid and $20 \mathrm{mM}$ hydrochloride and were eluted through a SepPak C18 cartridge (Waters Associates, Milford, Massachusetts, USA) (30). Blood was sampled from the retroorbital sinus of mice under slight anesthesia with ether. Serum LH concentrations at 2000 hours on the proestrus day, i.e., at the time of LH surge, were determined in female transgenic and nontransgenic littermates at 13-18 weeks of age. Serum LH response to exogenously administered GnRH was examined as described previously (31). Female transgenic and nontransgenic littermates were injected intraperitoneally with GnRH (3.3 ng/g body weight) (Sigma Chemical Co., St. Louis, Missouri, USA) on day 21 and at the diestrus stage at 13 weeks and 25 weeks of age. Blood was sampled 15 minutes after the injection and subjected to the measurement of serum LH concentrations.

Ovarian response to exogenously administered gonadotropins were assessed using 25-week-old female transgenic and nontransgenic littermates by intraperitoneal administration of pregnant mare serum gonadotropin (PMSG) (5 IU) on the diestrus day and human chorionic gonadotropin (hCG) (5 IU) 2 days later.

Hormone assays. Hypothalamic GnRH contents were measured by GnRH enzyme immunoassay kit (Peninsula Laboratories, Inc., Belmont, California, USA) according to the manufacturer's recommendation. Sensitivity of the assay was $0.02 \mathrm{ng} / \mathrm{mL}$. Coefficient of interand intra-assay variations were less than $14 \%$ and $5 \%$, respectively. Plasma leptin concentrations were determined using the RIA for mouse leptin (Linco Research Immunoassay, St. Louis, Missouri, USA). Sensitivity of the assay was $0.2 \mathrm{ng} / \mathrm{mL}$. Coefficient of inter- and intraassay variations were $5.9 \%$ and $4.0 \%$, respectively. Serum LH concentrations were measured using the RIA with rat LH standards (Amersham Pharmacia Biotech, Buckinghamshire, United Kingdom). Sensitivity of the assay was $0.2 \mathrm{ng} / \mathrm{mL}$. Coefficient of inter- and intra-assay variations were $6.6 \%$ and $6.5 \%$, respectively.

Histological studies. Ovaries, uteri, and testes were fixed in $10 \%$ formaldehyde, dehydrated with a graded series of ethanol, and embedded in paraffin. Sections of ovaries and uteri (5- $\mu \mathrm{m}$ thick) were stained with hematoxylin and eosin and examined by light microscopy. 
Statistical analysis. Significance was assessed by Student's $t$ test, $\chi^{2}$ test, Mann-Whitney's U-test, and logrank test, where indicated, and otherwise by ANOVA with Fisher's least significance difference test. All values were expressed as means \pm SEM.

\section{Results}

Plasma leptin concentrations in female transgenic skinny mice.

Plasma leptin concentrations in female transgenic skinny mice were approximately 10 -fold higher than those in nontransgenic littermates $(81.4 \pm 15.4$ vs. $9.2 \pm 2.2$ $\mathrm{ng} / \mathrm{mL} ; n=7$ and 5 , respectively, at 4 weeks of age) and were unchanged with age, as reported previously (27).

Reproductive phenotypes of female transgenic skinny mice at younger ages

Accelerated puberty. Vaginal opening in transgenic skinny mice occurred earlier than that in nontransgenic littermates $(27.3 \pm 0.5$ vs. $29.4 \pm 0.9 \mathrm{~d} ; n=9 ; P<$ 0.05 by log-rank test; Figure $1 \mathrm{a})$. At day 21 , ovarian weights of transgenic skinny mice were greater than those of nontransgenic littermates $(3.1 \pm 0.3$ vs. $2.2 \pm$ $0.2 \mathrm{mg} ; n=4$ and 7 , respectively; $P<0.01$; Figure $1 \mathrm{~b}$ ). Histological examination revealed that the ratio of the number of growing follicles (larger than $140 \mu \mathrm{m}$ in diameter), with several layers of granulosa cells, among all follicles were higher in arbitrary ovarian slices of transgenic skinny mice than those of nontransgenic littermates $(25.8 \pm 0.5$ vs. $17.9 \pm 1.0 \%$; $n=$ 3; $P<0.005$ by Mann-Whitney's U-test; Figure 2, a and e). At day 29, 1 transgenic mice of 4 was sacrificed and 1 nontransgenic littermate of 6 was sacrificed at the metestrus stage; the others were sacrificed at the diestrus stage. For these mice, ovarian maturation occurred at day 29 in both genotypes, and there were no significant differences in weight (Figure 1b) or histology (data not shown) between transgenic and nontransgenic littermates. The uterine weights of transgenic skinny mice were significantly greater than those in nontransgenic littermates $(22.3 \pm 1.6$ vs. $13.3 \pm 1.0 \mathrm{mg} ; n=4$ and 6 , respectively; $P<0.005$; Figure $1 \mathrm{c})$.

Hypothalamic GnRH contents at either day 21 or day 29 (Figure 3a) and serum LH response to exogenously administered GnRH at day 21 in transgenic skinny mice did not differ from those in nontransgenic littermates (Figure 3b).

Maintenance of intact fertility at younger ages. The fertility rate of transgenic skinny mice at 8 weeks of age did not differ from that of nontransgenic littermates (Table 1). They delivered healthy pups timely at day 19 of pregnancy. The numbers of pups did not differ between transgenic and nontransgenic littermates (Table 1). At 11 weeks of age, there were no significant differences in ovarian and uterine weights between genotypes (Figure 1, b and c, and Figure 2, b and f). The durations of the estrous cycles did not differ at 8 weeks of age ( $4.7 \pm 0.2$ vs. $5.4 \pm 0.8 \mathrm{~d} ; n=4)$ (Figure $1 \mathrm{~d})$. Hypothalamic GnRH contents in transgenic skinny mice did not differ from those in nontransgenic littermates at 11 weeks of age $(0.54 \pm 0.11$ vs. $0.62 \pm 0.15 \mathrm{ng} / \mathrm{hypo-}$ thalamus; $n=4$; Figure 3a).

Reproductive phenotypes of female transgenic skinny mice at older ages

Impaired reproductive function at older ages. The fertility rate of transgenic skinny mice was markedly reduced at 22 weeks of age (Table 1). The durations of estrous cycles were prolonged significantly in 30-week-old transgenic skinny mice compared with nontransgenic littermates $(10.2 \pm 1.6$ vs. $5.5 \pm 0.8 \mathrm{~d} ; n=5 ; P<$ 0.05 ; Figure $1 \mathrm{~d})$. In 21 -week-old transgenic skinny mice, ovarian weights were markedly reduced compared with those of nontransgenic littermates (7.8 \pm 0.3 vs. $10.8 \pm 0.5 \mathrm{mg} ; n=4 ; P<0.005$; Figure $1 \mathrm{~b}$ ). Histological examinations revealed that ovaries were atrophied in transgenic skinny mice, accompanied by a significant reduction in the number of mature antral follicles $(4.0 \pm 1.2 \mathrm{vs}$. $8.0 \pm 1.2$ per slice of unilateral ovary; $n=5 ; P<0.05$ by Student's $t$ test). In
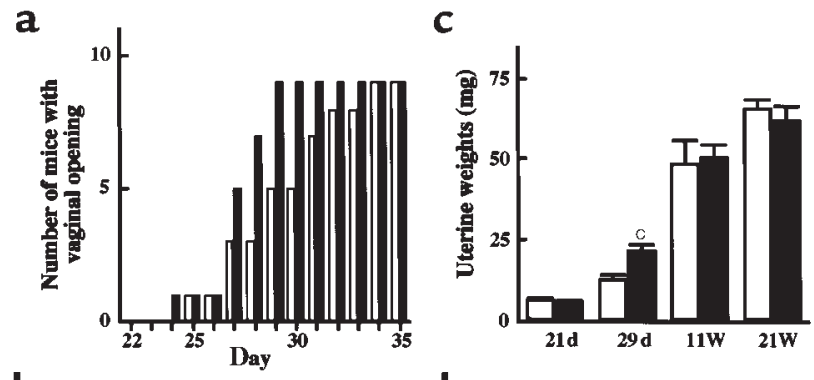

b
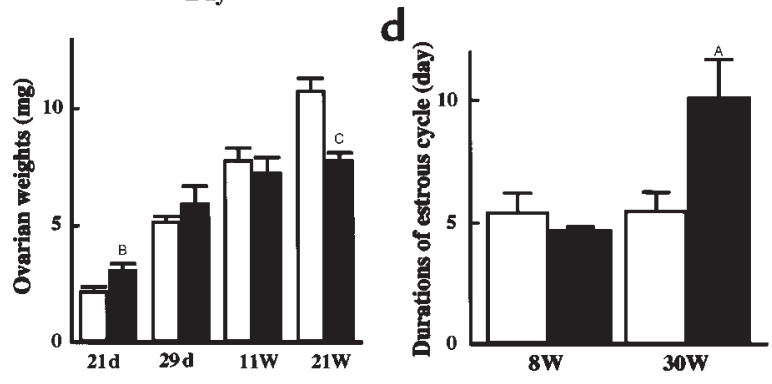

\section{Figure 1}

Reproductive profile of transgenic skinny mice overexpressing leptin (filled columns) and their nontransgenic littermates (open columns). (a) Number of mice with vaginal opening $(n=9) ; P<0.05$ by log-rank test. (b) Organ weights of ovaries on day 21 ( 21 d) (filled columns, $n=4$; open columns, $n=7$ ) day 29 ( $29 \mathrm{~d}$ ) (filled columns, $n=4$; open columns, $n=6)$, and on the diestrus day at 11 weeks (11W) (filled and open columns, $n=4$ ) and 21 weeks (21W) (filled and open columns, $n=4$ ) of age. (c) Organ weights of uteri. Uteri were collected from the same animals in $\mathbf{b}$. (d) Durations of estrous cycle by vaginal smears. Daily observation was performed for 20 days from 8 weeks ( $8 \mathrm{~W}$ ) (filled and open columns, $n=4)$ and 30 weeks $(30 \mathrm{~W}$ ) (filled and open columns, $n=5$ ) of age. ${ }^{A} P<0.05$, ${ }^{\mathrm{B}} P<0.01$, and ${ }^{\mathrm{C}} P$ $<0.005$ compared with nontransgenic littermates by ANOVA with Fisher's least significance difference test. 
extreme cases, growing follicles were absent (Figure 2, $\mathrm{c}$ and $\mathrm{g}$ ).

Suppressed hypothalamic pituitary activity at older ages. Hypothalamic GnRH contents in 21-week-old transgenic skinny mice were lower than those in nontransgenic littermates $(0.52 \pm 0.05$ vs. $0.92 \pm 0.11$ ng/hypothalamus; $n=4 ; P<0.05$; Figure $3 \mathrm{a}$ ). In addition, serum LH concentrations after GnRH administration in transgenic skinny mice were moderately but significantly lower than those in nontransgenic littermates (Figure $3 \mathrm{~b}$ ). The poor $\mathrm{LH}$ response, a reflection of chronic hypothalamic dysfunction, was observed in transgenic skinny mice as early as 13 weeks of age. Moreover, serum LH concentrations on the evening of proestrus day, i.e., at the time of $\mathrm{LH}$ surge, were markedly reduced in 13- to 18 -week-old transgenic skinny mice compared with nontransgenic littermates $(3.3 \pm 1.1$ vs. $29.4 \pm 6.8 \mathrm{ng} / \mathrm{mL} ; n=$ 6 and 4 , respectively; $P<0.005$ by Student's $t$ test; Figure 3c).

Intact response to ovarian stimulation at older ages. Ovarian sensitivity to exogenously administered gonadotropins was examined in 25 -week-old transgenic and nontransgenic littermates. Unilateral ovary was sampled and weighed before stimulation, confirming the reduced ovarian weight in transgenic skinny mice ( $3.3 \pm 0.3$ vs. $4.2 \pm 0.2 \mathrm{mg}$ for unilateral ovary; $n=3 ; P<0.05$ by Student's $t$ test). After 2 cycles of gonadotropin stimulation, ovaries of transgenic skinny mice became enlarged indistinguishably from those of nontransgenic littermates $(8.0 \pm 0.6$ vs. $9.8 \pm$ $0.8 \mathrm{mg}$ for remaining unilateral ovary; $n=3$ ). Ovaries of transgenic skinny mice responded to gonadotropins similarly to those of nontransgenic littermates ( $4.8 \pm 0.5$ vs. $4.5 \pm 0.3$ follicles, and $5.8 \pm$ 0.7 vs. $6.3 \pm 0.9$ corpus lutea per slice of unilateral ovary in transgenic and nontransgenic littermates, respectively; $n=3$; Figure 2, $\mathrm{d}$ and $\mathrm{h}$ ).

Reproductive phenotypes of male transgenic skinny mice at older ages.

To extend our observations on female transgenic skinny mice at older ages, we also examined the reproductive phenotypes of male transgenic skinny mice at older ages. The fertility rate of male transgenic skinny mice did not differ from that of nontransgenic littermates at 22 weeks of age (Table 1). The number of pups did not differ between genotypes (Table 1). In 26-week-old mice, there were no significant differences between transgenic and nontransgenic littermates in testicular weights ( $158.8 \pm 13.8$ vs. $168.8 \pm 6.3 \mathrm{mg} ; n=4)$ and histology (data not shown). Hypothalamic GnRH contents in 26-week-old transgenic skinny mice tended to be decreased compared with those in nontransgenic littermates ( $0.60 \pm 0.07$ vs. $0.78 \pm 0.07 \mathrm{ng} /$ hypothalamus; $n=4)$, but the difference was not significant $(P=0.11)$.

\section{Discussion}

Previous studies have demonstrated that an adequate mass of adipose tissue is required for proper onset of puberty and maintenance of fertility, suggesting an important link between energy homeostasis and reproductive function (1). However, the molecular mechanism whereby adipose tissue is involved in reproductive homeostasis has not fully been elucidated. This study demonstrates that at younger ages, female transgenic skinny mice overexpressing leptin exhibit accelerated puberty and maintain intact fertility, with no apparent adipose
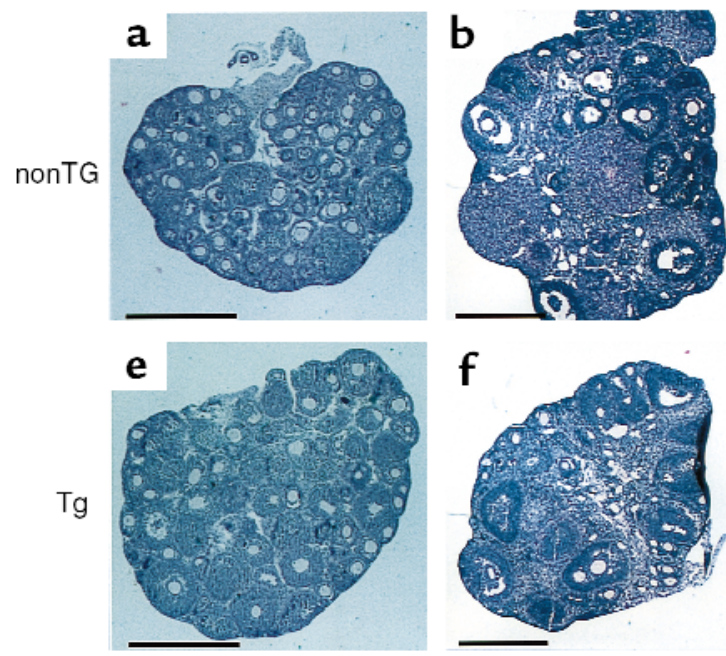

21d

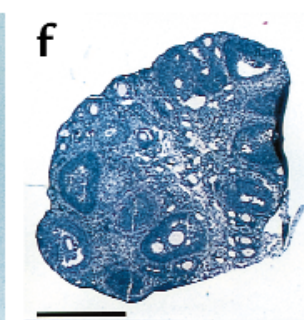

11 wk

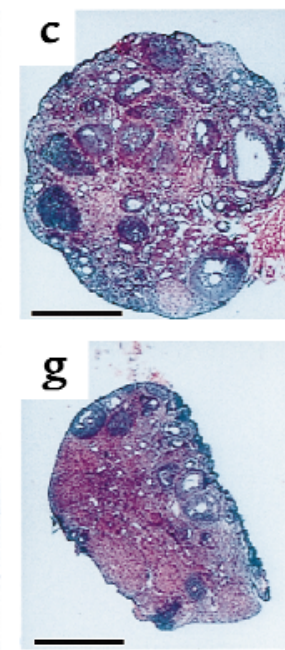

$17 w k$

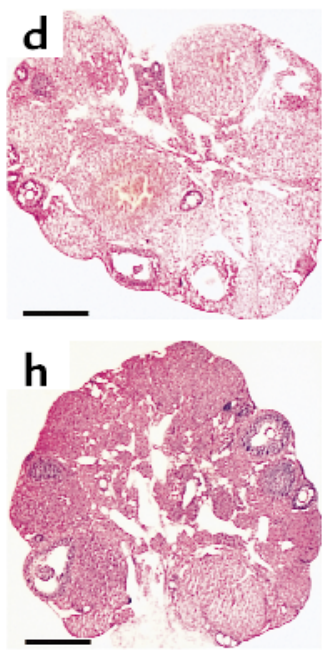

$25 w k$

Post stimulation

Figure 2

Gross histological findings of ovaries from transgenic skinny mice overexpressing leptin ( $\mathrm{Tg}$ : $\mathbf{e}-\mathbf{h})$ and their nontransgenic littermates (nonTg: a-d). Hematoxylin-eosin staining was performed on paraffin sections. $\mathbf{a}$ and $\mathbf{e}$ were collected from mice aged 21 days; $\mathbf{b}$ and $\mathbf{f}$ were from those aged 11 weeks; $\mathbf{c}$ and $\mathbf{g}$ were from those aged 17 weeks; and $\mathbf{d}$ and $\mathbf{h}$ were from those aged 25 weeks after 2 cycles of gonadotropin stimulation. Scale bar $=0.5 \mathrm{~mm}$. 
tissue. These mice exhibit earlier vaginal opening and greater uterine weights, suggesting the enhanced production of gonadal steroid hormones. Indeed, transgenic skinny mice show accelerated follicular development relative to nontransgenic littermates. These observations suggest that leptin is one of the major adipocyte-derived hormones determining the timing of puberty and maintaining intact fertility. Previous experimental studies demonstrated that exogenously administered leptin accelerated reproductive maturation in normal female mice fed ad libitum $(16,17)$, and maintained intact fertility in fasted mice and rats (18-20). However, there are several reports that leptin did not affect reproductive function in rats, ewes, and monkeys fed ad libitum $(20,32,33)$. The present study supports and confirms the stimulatory role of leptin on sexual maturation of the mouse reproductive system.

The mechanisms responsible for leptin-induced activation of reproductive homeostasis require further investigations. Leptin has been shown to increase $\mathrm{GnRH}$ and LH release from rat hypothalamic median eminence-arcuate nuclear explants in vitro (34). Furthermore, intracerebroventricular administration of leptin has been shown to induce sexual maturation in food-restricted rats (35). These findings suggest that leptin can modulate the reproductive function at least partly via hypothalamic function. In this study, there were no significant differences in hypothalamic pituitary function between transgenic and nontransgenic littermates during the course of puberty; this might be due to the pulsatility of hypothalamic $\mathrm{GnRH}$ production and thus pituitary LH production in vivo.

Unexpectedly, at older ages, female transgenic skinny mice exhibited reduced fertility. They showed increased locomotor activity and elevated body temperature with no signs of endocrine abnormalities associated with starvation or food restriction (Ogawa, Y. et al. unpublished data), such as increased adrenocorticotropic hormone levels or decreased thyroxine levels (18). Thus, the reproductive failure observed in female transgenic skinny mice at older ages may not be a result of reduced food intake or malnutrition. However, transgenic skinny mice showed decreased hypothalamic GnRH contents, together with an impairment in spontaneous $\mathrm{LH}$ surge and poor LH response to exogenously administered GnRH. These observations suggest that hypogonadism in female transgenic skinny mice at older ages is caused by hypothalamic rather than pituitary or gonadal dysfunction. In transgenic skinny mice at older ages, atrophied ovaries can be rescued by exogenous gonadotropins, suggesting that lack of primary follicles in ovaries is not a major cause of reproductive dysfunction. This discussion, however, does not exclude the possibility that leptin suppresses ovarian sensitivity to physiological levels of gonadotropins, as suggested by in vitro experiments (36).

Even at older ages, transgenic skinny mice remain hypophagic relative to nontransgenic littermates (27), suggesting that the effects of leptin on food

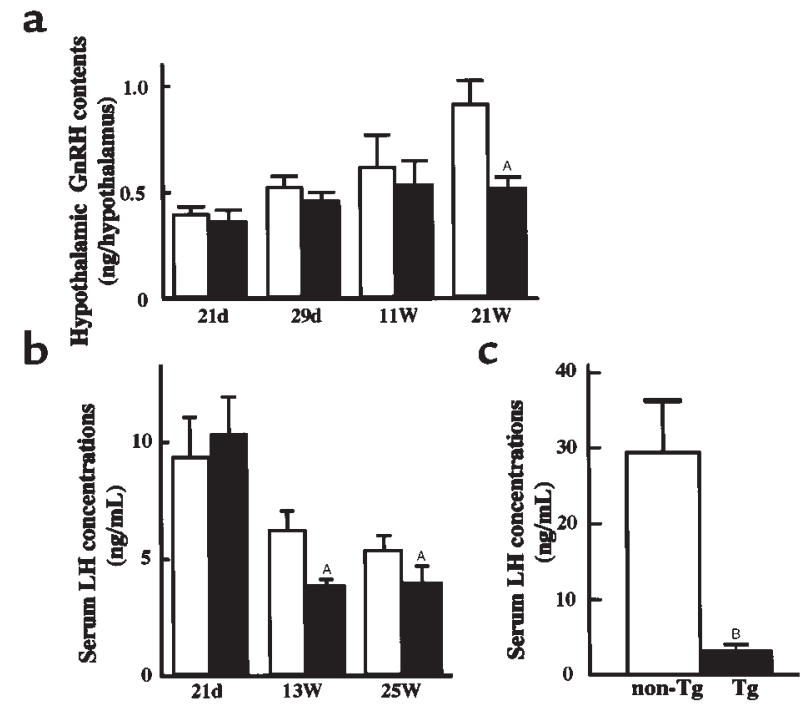

Figure 3

Hormonal profile of transgenic skinny mice overexpressing leptin (filled columns) and their nontransgenic littermates (open columns). (a) Hypothalamic GnRH contents. Hypothalami were collected from the same animals in Figure 1b. (b) Serum LH concentrations 15 minutes after intraperitoneal administrations of $\mathrm{GnRH}$. Procedures were performed on day 21 ( $21 \mathrm{~d}$ ) (filled columns, $n=10$; open columns, $n=8$ ), on the diestrus day at 13 weeks ( $13 \mathrm{~W}$ ) (filled columns, $n=6$; open columns, $n=4)$, and on the diestrus day at 25 weeks ( $25 \mathrm{~W}$ ) (filled and open columns, $n=10$ ) of age. (c) Serum LH concentrations at 2000 hours on the proestrus day between 13 and 18 weeks of age (filled columns, $n=6$; open columns, $n=4$ ). ${ }^{A} P<0.05$ compared with nontransgenic littermates by ANOVA with Fisher's least significance difference test. ${ }^{\mathrm{B}} P<0.005$ by Student's $t$ test.

intake and reproductive axis are mediated via different hypothalamic pathways as reported previously (33). We and others have demonstrated that the satiety effect of leptin is mediated at least partly through the hypothalamic melanocortin system (37, 38). Indeed, the melanocortin system is suppressed in leptin-deficient $o b / o b$ mice $(39,40)$, which show hyperphagia as well as infertility. However, lethal yellow agouti $\left(A^{y} / a\right)$ mice have been shown to be hyperphagic $(41,42)$ due to antagonism of the hypothalamic melanocortin system by ectopic expression of the agouti protein (43). Nevertheless, these mice develop puberty normally and maintain intact fertility after being hyperphagic (44), suggesting that leptin regulation of the reproductive axis does not require hypothalamic melanocortin system. This discussion is consistent with a notion that different thresholds exist for the different biologic effects of leptin (45). It has been reported that GnRH and LH secretion in vitro is stimulated at low doses of leptin but is not accelerated at higher doses (34). Collectively, these findings suggest that chronic hyperleptinemia may downregulate the hypothalamic leptin signaling to stimulate reproductive function, thereby leading to hypothalamic hypogonadism in transgenic skinny mice. 
In the present study, we also examined the reproductive phenotypes of male transgenic skinny mice at older ages and found that they showed no impairment of reproductive function. It has been reported that leptindeficient male $o b / o b$ mice occasionally become fertile after body weight reduction, whereas it never happens in female $o b / o b$ mice $(15,46)$. Furthermore, female $A y / a$ mice, which develop hyperleptinemia at older ages, develop infertility due to hypothalamic dysfunction, but male $A^{y} /$ a mice never develop reproductive failure at older ages $(47,48)$. These findings together suggest a gender difference in the effect of leptin on regulation of the reproductive function.

A large number of studies showed that plasma leptin concentrations are elevated significantly in obese subjects in proportion to the degree of adiposity, suggesting "leptin resistance" in obesity $(23-25,49,50)$. However, it is also possible that hyperleptinemia may play a role in the pathogenesis of obesity and obesity-related conditions. It is known that excess body fat in women often leads to hypothalamic hypogonadism (4). It is, therefore, tempting to speculate that chronic hyperleptinemia is involved in reproductive dysfunction in obese women.

In conclusion, we demonstrated accelerated puberty and late-onset hypothalamic hypogonadism in female transgenic skinny mice overexpressing leptin. This study provides the first elucidation of long-term effects of hyperleptinemia on the reproductive system, thereby leading to a better understanding of the pathophysiological and therapeutic implication of leptin.

\section{Acknowledgments}

We thank G. Katsuura, N. Satoh, and E. Matsutani for discussions; H. Iwai and H. Yoshida for technical assistance; and A. Kishimoto, Y. Isa, and Y. Nakajima for secretarial assistance. This work was supported in part by research grants from the Japanese Ministry of Education, Science, Sports, and Culture; the Japanese Ministry of Health and Welfare; the Yamanouchi Foundation for Research on Metabolic Disorders; the Mitsukoshi Fund of Medicine 1997; the Kowa Life Science Foundation; The Mitsubishi Foundation; The Naito Foundation; Uehara Memorial Foundation; Research for the Future of Japanese Society for the Promotion of Science (JSPS-RFTF 96100204 and 98L00801); and the Smoking Research Foundation, Japan.

1. Cameron, J.L. 1996. Nutritional determinants of puberty. Nutr. Rev. 54:s17-s22.

2. Bronson, F.H., and Manning, J.M. 1991. The energetic regulation of ovulation: a realistic role for body fat. Biol. Reprod. 44:945-950.

3. Frisch, R.E. 1984. Body fat, puberty and fertility. Biol. Rev. 59:161-188.

4. Azziz, R. 1989. Reproductive endocrinologic alterations in female asymptomatic obesity. Fertil. Steril. 52:703-725.

5. Bouvattier, C., Lahlou, N., Roger, M., and Bougneres, P. 1998. Hyperleptinaemia is associated with impaired gonadotrophin response to GnRH during late puberty in obese girls, not boys. Eur. J. Endocrinol. 138:653-658.

6. Spiegelman, B.M., and Flier, J.S. 1996. Adipogenesis and obesity: rounding out the big picture. Cell. 87:377-389.

7. Ailhaud, G., Grimaldi, P., and Negrel, R. 1992. Cellular and molecular aspects of adipose tissue development. Annu. Rev. Nutr. 12:207-233.

8. Zhang, Y., et al. 1994. Positional cloning of the mouse obese gene and its human homologue. Nature. 372:425-432.

9. Ogawa, Y., et al. 1995. Molecular cloning of rat obese cDNA and augmented gene expression in genetically obese Zucker fatty $(\mathrm{fa} / \mathrm{fa})$ rats. J. Clin. Invest. 96:1647-1652.

10. Pelleymounter, M.A., et al. 1995. Effects of the obese gene product on body weight regulation in $o b / o b$ mice. Science. 269:540-543.

11. Halaas, J.L., et al. 1995. Weight-reducing effects of the plasma protein encoded by the obese gene. Science. 269:543-546.

12. Campfield, L.A., Smith, F.J., Guisez, Y., Devos, R., and Burn, P. 1995. Recombinant mouse $O B$ protein: evidence for a peripheral signal linking adiposity and central neural networks. Science. 269:546-549.

13. Swerdloff, R.S., et al. 1978. The hypothalamic-pituitary axis in genetically obese $(o b / o b)$ mice: response to luteinizing hormone-releasing hormone. Endocrinology. 103:542-547.

14. Chehab, F.F., Lim, M.E., and Lu, R. 1996. Correction of the sterility defect in homozygous obese female mice by treatment with the human recombinant leptin. Nat. Genet. 12:318-320.

15. Mounzih, K., Lu, R., and Chehab, F.F. 1997. Leptin treatment rescues the sterility of genetically obese ob/ob males. Endocrinology. 138:1190-1193.

16. Chehab, F.F., Mounzih, K., Lu, R., and Lim, M.E. 1997. Early onset of reproductive function in normal female mice treated with leptin. Science. 275:88-90.

17. Ahima, R.S., Dushay, J., Flier, S.N., Prabakaran, D., and Flier, J.S. 1997. Leptin accelerates the onset of puberty in normal female mice. J. Clin. Invest. 99:391-395.

18. Ahima, R.S., et al. 1996. Role of leptin in the neuroendocrine response to fasting. Nature. 382:250-252.

19. Nagatani, S., et al. 1998. Evidence for GnRH regulation by leptin: leptin administration prevents reduced pulsatile LH secretion during fasting. Neuroendocrinology. 67:370-376.

20. Cheung, C.C., et al. 1997. Leptin is a metabolic gate for the onset of puberty in the female rat. Endocrinology. 138:855-858.

21. Ahima, R.S., Prabakaran, D., and Flier, J.S. 1998. Postnatal leptin surge and regulation of circadian rhythm of leptin by feeding. Implications for energy homeostasis and neuroendocrine function. J. Clin. Invest. 101:1020-1027.

22. Mantzoros, C.S., Flier, J.S., and Rogol, A.D. 1997. A longitudinal assessment of hormonal and physical alterations during normal puberty in boys. V. Rising leptin levels may signal the onset of puberty. J. Clin. Endocrinol. Metab. 82:1066-1070.

23. Frederich, R.C., et al. 1995. Leptin levels reflect body lipid content in mice: evidence for diet-induced resistance to leptin action. Nat. Med. 1:1311-1314.

24. Maffei, M., et al. 1995. Leptin levels in human and rodent: measurement of plasma leptin and $o b$ RNA in obese and weight-reduced subjects. Nat. Med. 1:1155-1161.

25. Considine, R.V., et al. 1996. Serum immunoreactive-leptin concentrations in normal-weight and obese humans. N. Engl. J. Med. 334:292-295.

26. Saad, M.F., et al. 1998. Diurnal and ultradian rhythmicity of plasma leptin: effects of gender and adiposity. J. Clin. Endocrinol. Metab. 83:453-459.

27. Ogawa, Y., et al. 1999. Increased glucose metabolism and insulin sensitivity in transgenic skinny mice overexpressing leptin. Diabetes. 48:1822-1829.

28. Masuzaki, H., et al. 1999. Glucose metabolism and insulin sensitivity in transgenic mice overexpressing leptin with lethal yellow agouti mutation. Diabetes. 48:1615-1622.

29. Suda, M., et al. 1998. Skeletal overgrowth in transgenic mice that overexpress brain natriuretic peptide. Proc. Natl. Acad. Sci. USA. 95:2337-2342.

30. Glass, J.D., and Dolan, P.L. 1988. Melatonin acts in the brain to mediate seasonal steroid inhibition of luteinizing hormone secretion in the white-footed mouse (Peromyscus leucopus). Proc. Soc. Exp. Biol. Med. 188:375-380.

31. Chandrashekar, V., Bartke, A., and Wagner, T.E. 1992. Neuroendocrine function in adult female transgenic mice expressing the human growth hormone gene. Endocrinology. 130:1802-1808.

32. Plant, T.M., and Durrant, A.R. 1997. Circulating leptin does not appear to provide a signal for triggering the initiation of puberty in the male rhesus monkey (Macaca mulatta). Endocrinology. 138:4505-4508.

33. Henry, B.A., et al. 1999. Central administration of leptin to ovariectomized ewes inhibits food intake without affecting the secretion of hormones from the pituitary gland: evidence for a dissociation of 
effects on appetite and neuroendocrine function. Endocrinology. 140:1175-1182.

34. Yu, W.H., Kimura, M., Walczewska, A., Karanth, S., and McCann, S.M 1997. Role of leptin in hypothalamic-pituitary function. Proc. Natl. Acad. Sci. USA. 94:1023-1028.

35. Gruaz, N.M., et al. 1998. Chronic administration of leptin into the lateral ventricle induces sexual maturation in severely food-restricted female rats. J. Neuroendocrinol. 10:627-633.

36. Zachow, R.J., and Magoffin, D.A. 1997. Direct intraovarian effects of leptin: impairment of the synergistic action of insulin-like growth factor-I on follicle-stimulating hormone-dependent estradiol-17 beta production by rat ovarian granulosa cells. Endocrinology. 138:847-850.

37. Seeley, R.J., et al. 1997. Melanocortin receptors in leptin effects. Nature. 390:349.

38. Satoh, N., et al. 1998. Satiety effect and sympathetic activation of leptin are mediated by hypothalamic melanocortin system. Neurosci. Lett. 249:107-110.

39. Schwartz, M.W., et al. 1997. Leptin increases hypothalamic pro-opiomelanocortin mRNA expression in the rostral arcuate nucleus. Diabetes. 46:2119-2123.

40. Thornton, J.E., Cheung, C.C., Clifton, D.K., and Steiner, R.A. 1997. Regulation of hypothalamic proopiomelanocortin mRNA by leptin in $o b / o b$ mice. Endocrinology. 138:5063-5066.

41. Bultman, S.J., Michaud, E.J., and Woychik, R.P. 1992. Molecular characterization of the mouse agouti locus. Cell. 71:1195-1204.
42. Miller, M.W., et al. 1993. Cloning of the mouse agouti gene predicts a secreted protein ubiquitously expressed in mice carrying the lethal yellow mutation. Genes Dev. 7:454-467.

43. Lu, D., et al. 1994. Agouti protein is an antagonist of the melanocytestimulating-hormone receptor. Nature. 371:799-802.

44. Granholm, N.H., and Brock, K.T. 1980. Effect of the lethal yellow gene $\left(A^{y}\right)$ on mating preference in C57BL/6J mice. Proc. SD Acad. Sci. 59:156-159.

45. Ioffe, E., Moon, B., Connolly, E., and Friedman, J.M. 1998. Abnormal regulation of the leptin gene in the pathogenesis of obesity. Proc. Natl. Acad. Sci. USA. 95:11852-11857.

46. Ewart, T.A., Mounzih, K., Qiu, J., and Chehab, F.F. 1999. Effect of the genetic background on the reproduction of leptin-deficient obese mice. Endocrinology. 140:732-738.

47. Kasten, F.H. 1952. Comparative histological studies of endocrine glands of yellow $\left(A^{y} a\right)$ and non-agouti $(a a)$ mice in relation to the problem of hereditary obesity. Science. 115:647-649.

48. Granholm, N.H., Jeppesen, K.W., and Japs, R.A. 1986. Progressive infertility in female lethal yellow mice (Ay/a; strain C57BL/6J). J. Reprod. Fertil. 76:279-287.

49. Caro, J.F., et al. 1996. Decreased cerebrospinal-fluid/serum leptin ratio in obesity: a possible mechanism for leptin resistance. Lancet. 348:159-161.

50. Schwartz, M.W., Peskind, E., Raskind, M., Boyko, E.J., and Porte, D.J. 1996. Cerebrospinal fluid leptin levels: relationship to plasma levels and to adiposity in humans. Nat. Med. 2:589-593. 